\title{
BOCCACCIO 70. IMÁGENES Y REPRESENTACIONES DE LA MUJER EN EL CINE ITALIANO
}

\author{
BOCCACCIO 70. IMAGES AND REPRESENTATIONS OF WOMEN IN ITALIAN \\ CINEMA
}

Laureano Núñez García

Universidad de Salamanca

\section{RESUMEN:}

A lo largo de la historia, se ha constatado que el cine italiano es una fuente importante para estudiar la sociedad de cada época; de esta forma, observamos cómo ha variado la imagen de la mujer y su rol en la sociedad. En este artículo se analiza la representación de la mujer en en el film italiano Boccaccio 70, una antología de episodios.

\section{Palabras clave:}

cine, Boccaccio 70, sociedad

\section{Abstract:}

Throughout history, it has been found that Italian cinema is an important source for studying the society of each era; In this way, we observe how the image of women and their role in society have changed. This article analyzes the representation of women in the Italian film Boccaccio 70, an anthology of episodes.

\section{KeywORDS:}

cinema, Boccaccio 70, society 
En un ensayo capital sobre la historia del cine italiano, Cinema italiano: gli anni '60 e oltre, su autor, el crítico e historiador Lino Micciché, sostiene que buena parte de la producción cinematográfica italiana de los años sesenta, y muy especialmente ese género o subgénero que se etiquetó como "commedia all'italiana", es más una fuente de argumentos y testimonios para el sociólogo y el historiador de la sociedad que para el historiador del cine o el especialista en estética (1995: 92). Y no le falta razón. El cine italiano de la década de los sesenta, junto con el cine neorrealista posbélico, se presentan como los dos momentos más brillantes de la aportación italiana a la cinematografía universal; con la particularidad de que la producción cinematográfica de los años sesenta evidenció y expresó, probablemente con más eficacia que otros productos culturales o artísticos de su época, la transición de una sociedad precapitalista a una sociedad industrial avanzada, en la que el boom económico propio de la década se consolidó con todas las implicaciones culturales, económicas y sociológicas que ello conllevaba. La mujer está inserta en este mismo cambio histórico de la sociedad italiana, y pensamos que no es exagerado afirmar que una lectura atenta del tratamiento que se hizo de la mujer en el cine, de los roles y de los estereotipos de la mujer, debería llevarnos a entender y calibrar el grado de evolución o involución de la sociedad italiana. Y éste es el objetivo fundamental de este trabajo en el que hemos optado por analizar la representación de la mujer (desde una perspectiva histórica y cultural) en el film Boccaccio 70, uno de los primeros y más interesantes filmes de episodios de la cinematografía italiana de la década que firmaron los directores Mario Monicelli, Federico Fellini, Luchino Visconti y Vittorio de Sica.

La elección de este film se justifica por una serie de razones de distinta índole. En primer lugar, es un film rodado en 1961, en el umbral de la década que transformará la realidad italiana, y en un momento en el que la importancia del mercado cinematográfico italiano, en cuanto a número de espectadores, era el mayor de Europa, lo que es enormemente significativo sobre la demanda de un producto cultural y de entretenimiento por parte de un nuevo y más amplio público urbano y burgués que en él se sentía reflejado. En segundo lugar, Boccaccio 70 supuso el lanzamiento de una nueva fórmula de concebir la producción de un film, precisamente el "film de episodios", integrando mediometrajes de distintos directores, a ser posible de renombre, hecho que unido a la participación de estrellas cinematográficas del momento garantizaran el éxito comercial del producto y redujeran los tiempos y la inversión en la producción. Boccaccio 70 es por tanto un film de episodios que permite confrontar la mirada particular de cuatro directores sobre un tema que en su idea primigenia pretendía dar vida a historias de carácter erótico-humorístico conceptualmente inspiradas en el espíritu del Decameron boccaccesco, historias concebidas como una sátira contra el moralismo y el puritanismo de la católica Italia de la época. El resultado final, sin embargo, evidenció una libertad absoluta de los distintos realizadores a la hora de 
crear sus mediometrajes, que no siempre se ajustaron al ideario boccaccesco, pero que en la mayoría de los casos se inspiran en textos literarios de la tradición europea, lo que confiere al film un atractivo mayor para nuestro análisis. En todo caso, Boccaccio 70 fue, quizá junto con el film Ro.Go.Pa.G, no sólo la primera sino también la obra que alcanzó una calidad artística y cultural más sobresaliente entre los más de cincuenta filmes de episodios de producción italiana que se estrenaron en la década de los sesenta.

La idea del film partió del guionista y cineasta Cesare Zavattini que se la propuso al productor Carlo Ponti quien, a su vez, siguiendo una lógica que garantizara una positiva rentabilidad comercial, apostó por reunir algunos de los directores y actrices más prestigiosos del momento: Mario Monicelli, director de I soliti ignoti (1958) y La grande guerra (1959) rueda el episodio Renzo e Luciana; Federico Fellini, de nuevo en colaboración con la actriz protagonista de La dolce vita (1960) Anita Ekberg, dirige el episodio Le tentazioni del dottor Antonio; Luchino Visconti, que con Rocco e i suoi fratelli ya había profundizado sobre la transformación en curso de la sociedad italiana dos años antes, dirige Il lavoro; y Vittorio de Sica recurre de nuevo a Sofia Loren con la que acababa de estrenar el film La ciocciara (1960) y firma el último episodio: La riffa.

La producción y el montaje del film tuvieron solo un incidente o contratiempo importante. Ante su excesiva duración (más de tres horas), el productor decidió eliminar el episodio de Mario Monicelli para la distribución en el extranjero, lo que motivó una sonada protesta de los otros tres directores cuando el film se presentó fuera de concurso en la 15a edición del Festival de Cannes. En España Boccaccio 70 no se estrenará hasta la desaparición del régimen franquista, en 1976.

El film inicia con el episodio Renzo y Luciana, escrito por los guionistas habituales de Monicelli, Giovanni Arpino y Suso Cecchi d'Amico, más la colaboración de Italo Calvino de cuyo cuento (Storia di due sposi, 1958) había surgido el motivo inspirador del episodio si bien la adaptación cinematográfica, mediante un proceso de adicción, alarga la historia y la inserta en un marco narrativo más amplio. El otro referente literario del episodio era lógicamente I promessi sposi de Manzoni, que inspira el título del episodio, y sobre cuyas implicaciones en una posible hermenéutica del mediometraje volveremos más adelante.

La historia narrada en Renzo e Luciana es, de manera sucinta, la siguiente: Renzo (Germano Gilioli) y Luciana (la actriz Marisa Solinas en su primer papel en el cine) son dos jóvenes obreros milaneses empleados en la misma empresa que se casan en secreto pues en el contrato de ella hay una cláusula que prohíbe a las empleadas casarse o quedarse embarazadas. Al principio la pareja vive en la casa de los padres de ella, pero la situación es cada día más incómoda y una vez que su relación es descubierta en la empresa deciden despedirse y, con el dinero de la liquidación, se trasladan a vivir a un apartamento. Aún así, la felicidad no es completa pues los horarios del 
nuevo trabajo de Luciana y de Renzo (vigilante nocturno), imposibilitan que la pareja coincida excepto en los cambios de turno de él y los domingos.

De los cuatro episodios de Boccaccio 70, Renzo e Luciana es, junto con el episodio Il lavoro de Visconti, el que menos se aviene al espíritu cómico-erótico boccaccesco que debería predominar en el film, y sin embargo, es quizás el que mejor refleje el proceso histórico de transformación de la realidad italiana de su época. En realidad todo el episodio puede entenderse como un ejemplo del impacto que el boom económico italiano de los sesenta ejerce sobre las clases trabajadoras, encarnadas en la joven pareja protagonista, y el precio que han de pagar, en su relación y en su vida cotidiana, para subirse al tren del bienestar que prometía la nueva sociedad industrial y capitalista que se estaba configurando.

Monicelli refleja la transformación económica del país a través de una serie de planos panorámicos de los nuevos escenarios urbanos: barriadas periféricas de nueva construcción, fábricas y empresas impersonales y masificadas (como se masifica el espacio del ocio: las piscinas o el cine), medios de transporte abarrotados que trasladan a los trabajadores por una anónima e irreconocible Milán que podría ser confundida con cualquier otra gran ciudad industrial del norte de Italia.

En este nuevo espacio urbano, tan alejado ya de cualquier imagen neorrealista, encontramos a la protagonista femenina del episodio, Luciana, una joven trabajadora de clase humilde que, como su predecesora manzoniana, detenta virtudes incuestionables: hermosa, honesta, emprendedora y sinceramente enamorada de Renzo; pero, en consonancia con el progreso económico de su época, su mayor aspiración no es únicamente casarse y formar una familia, sino luchar para alcanzar mayores niveles de bienestar y consumo. Rasgo característico de la personalidad de Luciana es la habilidad y la tenacidad con las que plantea todas sus acciones (y la de su joven marido) dirigidas a favorecer el ahorro e incrementar los ingresos. En este sentido su mentalidad es muy reveladora de los nuevos tiempos, pues aún conserva la idea tradicional de la mujerama de casa que hace progresar la economía doméstica a través del ahorro (y para ello no duda en renunciar a su viaje de novios) pero al mismo tiempo es consciente de que en una nueva economía monetaria capitalista, el dinero que se gana importa más que el que se gasta (Philippe Ariès- Gergoges Duby, 1991: 40), y de ahí su determinación a conservar el puesto de trabajo e incitar a Renzo a mejorar el suyo, hasta el punto que cuando en la empresa en la que trabajan despiden a Renzo por abrazarla, primero guarda silencio y después decide hacer pública su relación no por un acto de dignidad o solidaridad con el marido, sino por un simple cálculo monetario, que le lleva a pensar que es más ventajoso cobrar la indemnización por despido, dar la entrada para un piso y buscar un nuevo trabajo. 
Determinante en la vida de Luciana es, pues, precisamente el momento de transición entre lo viejo y lo nuevo de la sociedad italiana, en la que conviven ideologías y comportamientos fuertemente conservadores junto con innovaciones y avances en la condición de la mujer, como es su incorporación al mundo del trabajo.

Conservadora es aún, por ejemplo, la moral sexual que sólo a finales de la década empezará a liberalizarse y que se hace patente en el miedo de Luciana a confesar a sus padres la posibilidad de estar embarazada pues ello implicaba reconocer la existencia de relaciones previas al matrimonio en una sociedad en la que la virginidad era un valor intocable. La sumisión de la mujer a una jerarquía patriarcal y machista, se evidencia en la vida de Luciana más que en la relación con su marido, en el comportamiento de un padre autoritario e insensible, en el silencio que debe guardar ante la desconfianza del médico del seguro que amenaza con denunciarla en el caso de que esté embarazada $\mathrm{y}$ en el acoso al que le somete su superior en la empresa, un hombre prepotente y ridículo al que, como ya dijimos, solo se rebelará en el momento de ser despedida por un frío cálculo de interés económico.

La dialéctica confrontación entre lo viejo y lo nuevo en la sociedad italiana, está también presente en el episodio en la obsesiva aspiración de Luciana por conquistar un espacio propio donde poder hacer "una vida de pareja". Tradicionalmente las clases trabajadoras aceptaban compartir los espacios en los que convivir, siendo un lujo casi exclusivo de la burguesía disponer de un espacio mayor para su vida privada. También Renzo y Luciana deben aceptar en un primer momento instalarse en casa de los padres de ella, donde resulta imposible la más mínima intimidad, ni tan siquiera en la noche de bodas. Por ello, cuando finalmente la pareja consigue dar la entrada para el piso y vivir juntos (y solos), Luciana proclama lo afortunados que son al tiempo que calcula los recibos de la hipoteca que le faltan por pagar y renuncia a las vacaciones justificándose en que hay que" pensare al futuro"; pero Monicelli desmiente el ilusorio optimismo de Luciana en un plano secuencia en el que contemporáneamente vemos a Renzo, recién llegado del trabajo, preparando el café en la cocina para su mujer mientras Luciana, que acaba de levantarse, se arregla en el baño para ir al trabajo. El episodio termina con Renzo ocupando el espacio de la cama donde había dormido su mujer mientras ella se sube a un abarrotado autobús que la conduce al trabajo. En definitiva una nueva forma de separación, de incomunicabilidad en la pareja es el precio que deben pagar para adecuarse a las transformaciones en curso del milagro económico del país. De manera similar a I propessi sposi de Manzoni, como nos recuerda Leonardo Sciascia, lejos de ser un final feliz, supone para la pareja aceptar una nueva forma de separación, en la historia manzoniana de su tierra de origen, y en el episodio de Monicelli, de distanciamiento físico, que invierte el tono de comedia que había predominado en 
el episodio y sume al espectador en una desolada reflexión sobre los tiempos que se avecinan.

El segundo episodio de Boccaccio 70 lleva la firma de Federico Fellini y constituye un ejemplo paradigmático de las obsesiones temáticas y del vigor iconográfico que caracteriza el universo cinematográfico del director de Rimini. Parodiando el título de la obra de Flaubert (La tentation de Saint Antoine), Le tentazioni del dottor Antonio puede entenderse como un epílogo al anterior film del director (La dolce vita), una reacción airada y polémica contra las críticas por inmoralidad que desde la prensa vaticana y los ámbitos más católicos y conservadores se desencadenó contra el mítico film de 1960. En el episodio felliniano, el dottor Antonio (Pepino de Filippo) es un fervoroso e inflexible moralista ultracatólico obsesionado con la moral sexual de sus conciudadanos hasta el punto de molestar y denunciar a las parejas que buscan un poco de intimidad dentro de sus coches en las noches romanas. El problema surge cuando se coloca frente a su casa un enorme cartel publicitario que incita al consumo de leche con la fotografía de una exuberante y provocativa mujer (Anita Ekberg). Escandalizado y obsesionado, todos los intentos del dottor Antonio por hacer suprimir el cartel son infructuosos. Finalmente, una noche, Anita Ekberg se le aparece en forma de mujer real pero con el tamaño agigantado que ya tenía en el cartel; voluptuosa y frívola acosa y persigue al asustado Antonio que se debate entre el rechazo histérico y la atracción erótica. A la mañana siguiente el cartel publicitario aparece destrozado y el dottor Antonio es encerrado en un hospital psiquiátrico. En este episodio de Fellini la representación de la mujer presenta al menos dos aspectos interesantes. Por un lado, el papel de Anita Ekberg pertenece a una de las tipologías de mujer propias del cine felliniano, la de la mujer sexualmente poderosa, pura carnalidad, identificada con la tentación, ya analizada en numerosos trabajos [Colón Perales, 1994: 119]. Por otro, esta misma mujer está directamente vinculada a un fenómeno emergente de la época dirigido a incitar al consumo, la publicidad, lo que nos lleva a contextualizar el episodio atendiendo a las transformaciones propias de la sociedad italiana a principios de los años sesenta. Y efectivamente la representación de la protagonista femenina del episodio se nos presenta no como un personaje real o verosímil al que se le dota de un carácter propio, sino como una imagen convertida en símbolo, en una sociedad en la que el poder de lo icónico ha adquirido una importancia desconocida hasta entonces, y en este sentido es conveniente recuperar el sentido etimológico de la palabra imago, que antes de significar copia, imitación o reproducción (en este caso publicitaria), tenía en el latín arcaico la acepción de aparición o fantasma, que es como realmente se le aparece al atormentado dottor Antonio.

Anita Ekberg no es por tanto una mujer real ni aún cuando en el episodio pasa de imagen fotográfica a mujer de carne y hueso, sino una de las posibles variantes 
en las que Fellini concibe la condición femenina, es decir, la de la mujer diosa del sexo, presencia arcana y mitológica, carnal, desmesurada, una "Moby Dick del sexo" (Micciché, 1998: 266) en la que se concretizan todos los fantasmas que los hombres proyectan sobre la feminidad; la mujer inalcanzable que se sitúa siempre más allá de lo real y que, como en el episodio de Le tentazioni del dottor Antonio, más que seducir, se convierte en una visión de pesadilla que termina por enloquece al hombre (Colón Perales, 1994: 133). El hecho de que esta mujer tentadora y pecaminosa que atormenta al ridículo y reprimido Pepino de Filippo persiguiéndolo por las calles del barrio romano del EUR provenga de una imagen publicitaria no hace más que recalcar como en la sociedad contemporánea la imaginación se ve rodeada por imágenes externas y como todos nosotros participamos de los fantasmas colectivos. La imagen publicitaria, que a partir de la década de los sesenta adquiere un papel fundamental a la hora de difundir nuevas formas de consumo, lleva implícita unos nuevos valores y normas, un no disimulado culto al cuerpo, a la belleza y al erotismo, y la censura icónica que en un momento determinado puede surgir sobre ella, como nos recuerda Román Gubert, es consecuencia de la eficacia emocional de las imágenes, de su capacidad turbadora (2004: 11).

El tercer episodio de Boccaccio 70, Il lavoro, es obra del director Luchino Visconti, que escribió también el guión con la colaboración de Suso Cecchi d'Amico a partir del cuento de Guy de Maupassant Au bord du lit. Como ya sucediera con el episodio de Monicelli, Il lavoro indaga en la relación de pareja de un joven matrimonio milanés alejándose también del tono erótico-humorístico que debía haber inspirado la realización del film. Si bien en un principio el episodio de Visconti respeta el texto literario de Maupassant, a partir de un cierto momento la historia pierde el tono libertino del original para plantearnos una amarga reflexión sobre la decadencia de una clase social, la aristocracia y la alta burguesía de su tiempo, que relaciona el episodio más que con el escritor francés con una larga tradición literaria, también milanesa, de sátira antiaristocrática, que se remonta como mínimo a Giuseppe Parini y a Carlo Porta.

Il lavoro narra, con un tono realista y a menudo descarnadamente cínico, el conflicto que surge en el aristocrático matrimonio compuesto por el conde Ottavio (Thomas Milian) y la hija de un adinerado industrial alemán, la bella Pupe (Romy Schneider), cuando los periódicos sensacionalistas sacan a la luz el morboso escándalo en el que está envuelto el marido por sus aventuras con prostitutas de lujo. Aconsejado por sus abogados el conde intenta minimizar lo sucedido ante su joven esposa, quien a su vez se plantea la posibilidad de encontrar un trabajo que de más sentido a su anodina vida; pero descartada esta última iniciativa, bien por incapacidad o porque no desea renunciar a los privilegios de su posición, a Pupe sólo se le ocurre proponer a su marido que le pague por mantener relaciones sexuales con ella igual que hacía con las 
prostitutas, en un intento de provocar alguna reacción en su marido, que sin embargo acepta encantado la propuesta mientras ella debe aceptar entre lágrimas esta nueva forma de humillación.

Il lavoro se presenta, por tanto, como un nuevo intento en la cinematografía de Visconti por profundizar en el análisis de una doble descomposición: la de la institución familiar, como ya ocurriera en Rocco e i suoi fratelli, pero ahora centrada en su núcleo más básico, la pareja; y al mismo tiempo la descomposición de una clase social, la alta sociedad, tema que retomará magistralmente un año después en Il Gatopado (1963). La protagonista femenina del episodio, Pupe, encarna a la perfección el prototipo de mujer de la alta burguesía a la que ni el dinero ni la posición social le aportan un mínimo de libertad personal ni la posibilidad de autorrealizarse. Todo el episodio de Il lavoro está rodado en interiores, en el lujoso palacio en el que habita el matrimonio, pero todo el esplendor formal y la fastuosa puesta es escena de la que es capaz Visconti (que es mucha) no hace más que incidir sobre la condición de callejón sin salida, de "abismo infernal" (Micicché, 1998: 258), de prisión física, psicológica y sentimental, en la que se encuentra sumida la pareja protagonista. La soledad de Pupe, la absoluta imposibilidad de establecer una comunicación sincera con ninguna de las personas que le rodean, que no son otras que los numerosos abogados de su marido y el servicio doméstico, y su propia incapacidad para reaccionar al comportamiento del marido, conducen al espectador a vislumbrar el profundo vacío existencial de esta mujer. Pero en este duro análisis de las relaciones de pareja, Visconti demuestra no tener compasión por ninguno de los dos cónyuges. Si es cierto que en un primer momento Pupe se presenta como el personaje injustamente ofendido por el inaceptable comportamiento de su marido, es igualmente cierto que ella es plenamente consciente de que su matrimonio está cimentado sobre un oscuro trasfondo de intereses económicos, un contrato de conveniencia social, de clase según el cual el conde aportaba el prestigio del linaje y su padre el dinero necesario para mantener el alto nivel de vida, hasta el punto de que en una escena del episodio Pupe llega a decirle a Ottavio que el verdadero matrimonio lo forman él y su padre. Y ante esta realidad Pupe no se atreve o no es capaz de asumir una actitud de dignidad personal que invierta y haga desaparecer la condición de tedio y humillación en la que se encuentra su vida. Pupe, adiestrada para mantener en todo momento la compostura hipócrita y altiva que le confiere su posición social (y prueba de ello es el tono desdeñoso y ofendido en que pregunta a un abogado del marido si cree que ella tiene la mentalidad de una burguesa de provincia) sólo sabe contrariar al marido con comentarios mordaces aparentemente desenfadados y provocándole eróticamente. En realidad el binomio sexo-dinero es sin duda la fuerza motriz del drama y será también su resolución (Miret Jorba, 1989: 132). Cuando Pupe decida infantilmente encontrar un trabajo remunerado para el que carece absolutamente de preparación y voluntad y solo sea capaz de proponer a su marido que le pague la 
misma cantidad que a las prostitutas que frecuenta por acostarse con ella, en realidad no se puede tratar nada más que de un juego presuntamente terapéutico contra el aburrimiento, y como tal carente de motivo (Miret Jorba, 1989: 132). Las lágrimas de Pupe mientras espera a su marido en el dormitorio, una vez que ambos han aceptado el juego con las que finaliza el episodio, podrían hacernos pensar en una última e inesperada toma de conciencia por parte de la mujer de la humillación en la que se encuentra, pero el propio Visconti deseó aclarar, en la introducción al guión, que "no son lágrimas de salvación, sino lágrimas de orgullo, de quien no quiere, no sabe o no tiene la fuerza para liberarse de su propia condición humana y social", a lo que añade Visconti "sería necesaria una gran purga, pero falta Robespierre" (cit. Miret Jorba, 1989: 133).

De todos los episodios de Boccaccio 70, el cuarto y último, La riffa, de Vittorio de Sica, es sin duda el que con más acierto y fidelidad nos sumerge en el espíritu del Decameron boccaccesco con una visión alegre, cómica y desenfada de la relación más universal que existe, la del amor y el erotismo. A partir de un guión de Cesare Zavattini, La riffa nos sitúa en un ambiente campesino de la Emilia Romagna, en la pequeña localidad de Lugo, donde tiene lugar una feria ganadera. La explosiva Zoe (Sofia Loren), regenta junto con su hermana y su cuñado una atracción de feria de tiro con escopeta, pero como el negocio es insuficiente para vivir y las deudas amenazan el embargo, desde hace tiempo han ideado una rifa clandestina de gran éxito cuyo premio (en coincidencia con la extracción de il lotto de Nápoles) es una noche de amor con la propia Zoe. Después de vender la mayoría de los billetes entre los rudos y excitados ganaderos de la feria, el vencedor resulta ser el sacristán del pueblo, un hombre apocado y tímido que sin embargo rechaza las numerosas ofertas que le hacen para comprarle su billete ganador. Cuando pasa a recoger su premio por la caravana, un joven, de quien Zoe está enamorada, secuestra la caravana con ellos dentro y la conduce hasta el campo. La mujer despide al sacristán dándole el dinero que había ahorrado y finalmente puede pasar la noche con el hombre que ella desea.

De esta divertida historia coral, ejemplo paradigmático de la antigua alegría de vivir y de disfrutar del pueblo (en un sentido que podríamos definir pasoliniano), el personaje de Zoe se yergue como la única protagonista del relato, presencia femenina viva y concreta y al mismo tiempo llena de seducción, espléndida imagen del deseo para el conjunto de los habitantes varones de la localidad. El personaje de Zoe, al que la actriz Sofia Loren consigue trasmitir un carácter y una carnalidad absolutamente popular, es finalmente la encarnación de la libertad y la inteligencia práctica con las que Boccaccio había definido en muchos de sus cuentos la condición femenina. Y así, si acepta ser el premio de la rifa lo hace libremente, por un lado para ayudar a su hermana enferma y embarazada y, por otro lado, por la ausencia de prejuicios a la hora 
de conseguir un dinero que pretende ahorrar para casarse un día con el hombre que ella elija. Es verdad que Zoe es consciente de su atractivo físico y de las reacciones que produce en los hombres, pero a diferencia de otros personajes femeninos de Boccaccio 70, como el personaje de Anita Ekberg en el episodio de Fellini, su erotismo no es una sublimación onírica y amenazadora que, por exceso, intimide y desconcierte a los hombres hasta convertirse en una pesadilla, sino que se trata más bien de una sensualidad real, de una belleza con la que el azar premia a algunas personas casi en contra de su voluntad, sin que ello cambien su psicología o su comportamiento. Además, la naturaleza auténticamente popular del personaje de Zoe se manifiesta en su capacidad de relacionarse con todas las personas por igual, en no dejarse intimidar ni por las circunstancias ni por rostros duros, curtidos por el sol y encendidos por el vino y el deseo de los aldeanos que esperan ansiosos vencer la rifa. A diferencia de la Pupe del episodio de Visconti, Zoe sí es capaz de reaccionar ante cualquier situación y elegir libremente lo que más le convenga. No es sólo cuestión de astucia o necesidad de adaptarse al medio y a las circunstancias en las que le ha tocado vivir. En Zoe está presente también una sincera forma de generosidad, una empatía absolutamente femenina, y un buen conocimiento de la condición humana. También, lógicamente, de la psicología masculina. Cuando se encierra con el sacristán en la caravana, y decide generosamente entregarle todos sus ahorros como compensación por no disfrutar de su premio y mandarlo de vuelta a su casa, le concede el deseo de guardarle el secreto y poder así alardear ante sus conciudadanos de su proeza. Será ella, en cambio, quien disfrute libremente del amor con el hombre a quien ama, como un triunfo de la juventud, de la autenticidad de los instintos, mientras en el pueblo se forma una comitiva ruidosa y triunfal que lleva en volandas al sacristán y las viejas increpan a sus hijos y maridos desde las ventanas llamándolos "porci". En definitiva, alegría popular y reivindicación del amor y del sexo siguiendo la lección del magistral texto de Boccaccio. Y, desde luego, la mujer en igualdad de condiciones del hombre. O quizás un poco más.

\section{REFERENCIAS BIBLIOGRÁFICAS}

Ariès, F., - Duby, G., (dirección), Histoire de la vie privée, París, editions du Suil, 1987; ed. esp. consultada: Historia de la vida privada. La vida privada en el siglo XX, Madrid, Taurus, 1991.

Brunetta, G.P., Storia del cinema italiano dal 1945 agli anni ottanta, Roma, Editori Riuniti, 1982.

Colón Perales, C., Fellini o lo fingido verdadero, Sevilla, Alfar, 1994 (1989). Costa, A., Saper vedere il cinema, Milano, Bompiani, 1985.

Gubert, R., Historia del cine, Barcelona, Lumen, 1989. 
----, Patología de la imagen, Barcelona, Anagrama, 2004.

Micciché, L., Cinema italiano: gli anni '60 e oltre, Venezia, Marsilio, 1998 (1995). Miret Jorba, R., Luchino Visconti: la razón y la pasión, Barcelona, Dirigido por, 1989. Kezich, T., Fellini: la vida y las obra, Barcelona, Tusquets, 2007.

Sciascia, L., “Goethe e Manzoni” (Cruciverba), en Opere 1971-1983, Milano, Bompiani, 1989. 